\begin{tabular}{c|c|c}
\hline \hline Vol. 247: 137-149, 2003 & $\begin{array}{c}\text { MARINE ECOLOGY PROGRESS SERIES } \\
\text { Mar Ecol Prog Ser }\end{array}$ & Published February 4 \\
\hline
\end{tabular}

\title{
Predator avoidance by nauplii
}

\author{
Josefin Titelman $^{1,2,3, *}$, Thomas Kiørboe ${ }^{1}$ \\ ${ }^{1}$ Danish Institute for Fisheries Research, Department of Marine Ecology and Aquaculture, Kavalergården 6, \\ 2920 Charlottenlund, Denmark \\ ${ }^{2}$ Göteborg University, Department of Marine Ecology, Kristineberg Marine Research Station, 45034 Fiskebäckskil, Sweden \\ ${ }^{3}$ Present address: Plymouth Marine Laboratory, Prospect Place, The Hoe, Plymouth PL1 3DH, United Kingdom
}

\begin{abstract}
We examined anti-predation strategies in relation to motility patterns for early and late nauplii of 6 species of copepods (Calanus helgolandicus, Centropages typicus, Eurytemora affinis, Euterpina acutifrons, Acartia tonsa and Temora longicornis). Remote detection and escape abilities were quantified in siphon flows. Nauplii respond with distinct escape jumps at species- and stagespecific average fluid deformation rates between 0.5 and $4.2 \mathrm{~s}^{-1}$, and escape with average velocities corresponding to $\sim 60$ to 130 body lengths $\mathrm{s}^{-1}$. Most of the species and stages orient their escape jumps upwards and also away from the flow, and are thus able to assess direction of flow. Sensitivity to hydrodynamic signals is tightly linked to the general motility pattern. Hydrodynamically conspicuous nauplii that move in a jump-sink pattern are more effective at remotely detecting predators than are continuous swimmers of similar size. We assessed the effects of different motility strategies in terms of detectability and volume encounter with copepod predators by means of simple hydrodynamic models. While jump-sink type nauplii may be at an advantage over swimmers in interactions with sinking and attacking ambush predators, models suggest no immediate relative benefit in terms of escaping flows of filtering copepods. We discuss these predictions in relation to copepod feeding rates.
\end{abstract}

KEY WORDS: Copepod $\cdot$ Nauplii $\cdot$ Escape jump $\cdot$ Predator avoidance $\cdot$ Behavior $\cdot$ Motility $\cdot$ Hydrodynamic signals $\cdot$ Remote detection $\cdot$ Predator-prey interaction $\cdot$ Volume encounter rates $\cdot$ Encounter rates

Resale or republication not permitted without written consent of the publisher

\section{INTRODUCTION}

Most organisms move to encounter food (or other targets). However, food search is a dangerous affair because motility also implies enhanced encounter rates with predators by increasing the velocity difference between predator and prey. The 2 most extreme hunting strategies are tightly connected to motility, and are common in predators across animal groups and ecosystems. At one extreme are ambush predators that employ sit-and-wait tactics and rely on prey motility for encounter. At the other end of the spectrum are constantly moving predators that feed on whatever prey that comes in their way, be they motile or non-motile. These contrasting behaviors imply different encounter rates with potential predators.
In pelagic environments, prey face an additional challenge in that every move they make is reflected in the generation of hydrodynamic disturbances that can be detected by predators such as chaetognaths (Saito \& Kiørboe 2001) and copepods (Tiselius et al. 1997, Kiørboe \& Visser 1999). By moving, zooplankton prey therefore enhance their detectability (Titelman 2001) in addition to contributing to the velocity difference between predator and prey. Here, we examine the predation-related costs and trade-offs associated with different zooplankton prey motility strategies using copepod nauplii as model prey.

Some nauplii spend almost all their time motionless, while others move constantly (Paffenhöfer et al. 1996). Motility strategies reflect somewhat different adaptations to food encounter (Titelman \& Kiørboe 2003, this issue), but may also be associated with different preda- 
tion risks. Naupliar motility patterns are specific to both species and developmental stage (Fig. 1) (e.g. Buskey et al. 1993, van Duren \& Videler 1995, Paffenhöfer et al. 1996, Titelman \& Kiørboe 2003). However, 2 general motility types can be distinguished: viz., a jump-sink type, which punctuates long periods of sinking with brief fast jumps and relies on motile prey for food encounter, and a type that cruises more or less continuously and which is independent of prey motility for food acquisition (van Duren \& Videler 1995, Paffenhöfer et al. 1996, Titelman \& Kiørboe 2003).

These motility strategies generate fluid disturbances of very different magnitude and hence, imply very different exposures to predation risk. There is thus a behavioral trade-off between feeding and predator avoidance involved in the general behavior of nauplii or any other small zooplankton prey. A small number of laboratory studies have clearly demonstrated effects of prey motility on copepod predator detectability and/or encounter rates with various zooplankters as prey; i.e. nauplii (Titelman 2001), copepods (Kerfoot 1978, Tiselius et al. 1997), cladocerans (Kerfoot 1978) and ciliates (Broglio et al. 2001).

On the other hand, nauplii and other zooplankton prey may also detect an approaching predator remotely by means of the hydrodynamic signal generated by the predator, and respond by performing powerful escape jumps (e.g. Haury et al. 1980, Fields \& Yen 1997a,b, Kiørboe et al. 1999, Jakobsen 2001). Consequently, predation mortality, here expressed as a predator clearance rate $(F)$, is a function of both the volume encounter rate $(\beta)$ and the probability of prey escape $(p)$ given an encounter with a copepod predator (e.g. Greene 1988):

$$
F=\beta(1-p)
$$

where $\beta \propto R^{2} \Delta v_{i} R$ is the predator's detection distance and $\Delta v$ is the velocity difference between prey and predator (e.g. Kiørboe \& Saiz 1995). For definition of symbols, see Table 1. Hence, small zooplankters may employ behavioral strategies that influence their predation risk through effects on all of $R_{r} \Delta V$ and $p$.

We examine the hypothesis that hydrodynamically conspicuous nauplii compensate for their higher risk
Table 1. Glossary. Subscripts sink, jump, swim and move occur throughout the text where move can be either swim or jump behavior, and indicate that the parameter is behavior specific. Parameters that are behavior specific are indicated with a subscript $\mathrm{i}$ in the table and the text. Dimensions are L for length and $\mathrm{T}$ for time

\begin{tabular}{|c|c|c|}
\hline Symbol & Meaning & Dimensions \\
\hline$A$ & Amplitude of helix & $\mathrm{L}$ \\
\hline a & Equivalent radius of prey & $\mathrm{L}$ \\
\hline$C$ & Predator or collector radius & $\mathrm{L}$ \\
\hline$F$ & Predator clearance rate & $\mathrm{L}^{3}$ ind ${ }^{-1} \mathrm{~T}^{-1}$ \\
\hline$f_{\text {jump }}$ & Jump frequency & $\mathrm{T}^{-1}$ \\
\hline$f_{\text {loop }}$ & Loop frequency & $\mathrm{T}^{-1}$ \\
\hline 1 & Copepod cephalothorax length & $\mathrm{L}$ \\
\hline$p$ & Probability of prey escape & Dimensionless \\
\hline$Q$ & Volume flow rate & $\mathrm{L}^{3} \mathrm{~T}^{-1}$ \\
\hline$r$ & Distance & $\mathrm{L}$ \\
\hline$R_{\mathrm{i}}$ & Distance at which predator detects prey & $\mathrm{L}$ \\
\hline$R_{\text {naup }}$ & Distance at which a prey detects a predator & $\mathrm{L}$ \\
\hline $\mathrm{R}_{\text {pred-i }}$ & $\begin{array}{l}\text { Prey detectability (i.e. distance at which } \\
\text { predator detects a prey) }\end{array}$ & $\mathrm{L}$ \\
\hline$s_{\Delta^{*}}$ & Signal strength due to critical deformation & $\mathrm{L} \mathrm{T}^{-1}$ \\
\hline$t_{i}$ & Fraction time spent in a specific behavior & Dimensionless \\
\hline$U$ & Maximum feeding current velocity & $\mathrm{L} \mathrm{T}^{-1}$ \\
\hline$u$ & Predator velocity & $\mathrm{L} \mathrm{T}^{-1}$ \\
\hline$u^{*}$ & $\begin{array}{l}\text { Threshold velocity required for predator } \\
\text { to respond }\end{array}$ & $\mathrm{L} \mathrm{T}^{-1}$ \\
\hline$U_{c r}$ & Critical sinking velocity of predator & $\mathrm{L} \mathrm{T}^{-1}$ \\
\hline$v_{i}$ & Prey velocity & $\mathrm{L} \mathrm{T}^{-1}$ \\
\hline$V_{\text {move }}$ & Prey move speed & $\mathrm{L} \mathrm{T}^{-1}$ \\
\hline$V_{\text {transport }}$ & $\begin{array}{l}\text { Prey transport speed along helical axes of } \\
\text { a swimming trail }\end{array}$ & $\mathrm{L} \mathrm{T}^{-1}$ \\
\hline$w$ & Copepod cephalothorax width & $\mathrm{L}$ \\
\hline$\beta$ & Volume encounter rate & $\mathrm{L}^{3}$ ind. ${ }^{-1} \mathrm{~T}^{-1}$ \\
\hline$\beta_{i}$ & $\begin{array}{l}\text { Behavior specific volume encounter rate, } \\
\text { normalized with } t_{i}\end{array}$ & $\mathrm{~L}^{3}$ ind. ${ }^{-1} \mathrm{~T}^{-1}$ \\
\hline$\beta_{\text {tot }}$ & Total predator volume encounter rate & $\mathrm{L}^{3}$ ind. ${ }^{-1} \mathrm{~T}^{-1}$ \\
\hline$\Delta^{*}$ & Critical fluid deformation rate & $\mathrm{t}^{-1}$ \\
\hline$\Delta v_{i}$ & $\begin{array}{l}\text { Velocity difference between predator } \\
\text { and prey }\end{array}$ & $\mathrm{L} \mathrm{T}^{-1}$ \\
\hline$\theta$ & Angle relative to prey & $\circ$ \\
\hline$\theta_{\text {flow }}$ & Escape angle relative to flow line & $\circ$ \\
\hline$\theta_{\text {horiz }}$ & Escape angle relative to horizontal plane & $\circ$ \\
\hline$\varnothing$ & Diameter & $\mathrm{L}$ \\
\hline
\end{tabular}

of encountering a predator by being better at detecting and/or escaping predator hydrodynamic signals, when compared to nauplii exhibiting a more silent motility. That is, nauplii that elicit a large $\beta$ compensate by a high $p$ in Eq. (1). To test this hypothesis, we quantify perception and escape abilities of late and early nauplii stages of 6 species of copepods by investigating their behavioral response in a flow field. We then estimate the hydrodynamic 'noise' generated by the same nauplii based on published observations of their motility (Titelman \& Kiørboe 2003). Finally, we examine differences between motility types in interactions between nauplii and copepod predators. 


\section{MATERIALS AND METHODS}

We experimentally quantified the reaction to hydrodynamic signals and the escape jump behavior of early and late naupliar stages of 4 copepod species, Calanus helgolandicus, Centropages typicus, Eurytemora affinis and Euterpina acutifrons, and expanded our data source with observations on Acartia tonsa and Temora longicornis nauplii from the literature (Kiørboe et al. 1999, Titelman 2001). Experimental animals were provided from cultures (Titelman \& Kiørboe 2003).

Set-up and experimental procedure. We assessed the ability of a nauplius to perceive hydrodynamic signals by determining the fluid deformation rate required to elicit an escape response. The fluid deformation rate is the component of the predator-generated flow that smaller nauplii (and copepod) prey respond to when detecting a larger predator (Kiørboe \& Visser 1999, Kiørboe et al. 1999). We exposed nauplii to a radially symmetric suction flow field created by a pipette, and noted start and end positions of their escape jumps (Fields \& Yen 1997a, Kiørboe et al. 1999). For each escape event, we also measured escape speed, distance and direction.

Kiørboe et al. (1999) describe the pipette set-up and associated theory in detail. Briefly, it consists of an aquarium with a Pasteur pipette (1.1 $\mathrm{mm}$ in diameter) mounted in the bottom through which a gravity driven flow passes. To avoid variations in the flow field due to changes in pressure, we used a large total head and restricted the run time of the trials ( $10 \mathrm{~min}$ ) (cf. Kiørboe et al. 1999). The aquarium was submerged into an outer aquarium in order to stabilize temperature and limit convection. Experiments were conducted in a temperature-controlled room $\left(18^{\circ} \mathrm{C}\right)$. All experiments were filmed using a 3D video filming set up with perpendicularly mounted cameras connected to a synchronizer, a mixer, a monitor and a VCR (Viitasalo et al. 1998, Titelman \& Kiørboe 2003). Collimated light from 2 IR diodes provided the only light source.

Nauplii were transferred to the experimental aquarium ( $0.2 \mu \mathrm{m}$ filtered seawater) at concentrations of 1 to $5 \mathrm{ml}^{-1}$. We tested early and late naupliar stages of each species in 2 to 4 (normally 3 ) trials. In most cases, the nauplii were drawn from the same culture batch, but in some cases from 2 to 3 cultures. The likelihood of each individual being recorded twice is very low at these low naupliar concentrations and short time durations of the experiment. All observations of the same stage and species of nauplii were pooled. Samples of nauplii were staged and sized in each experiment (Table 2).

Data analysis. Videos were analyzed frame by frame for start and end points of escape jumps $(x, y, z)$, from which the critical deformation rate required to induce a response, jump speed, jump distance and jump direction were quantified. In cases where nauplii escaped but got caught in the flow again and responded repeatedly, only the first reaction was considered. Likewise, where nauplii conducted a series of

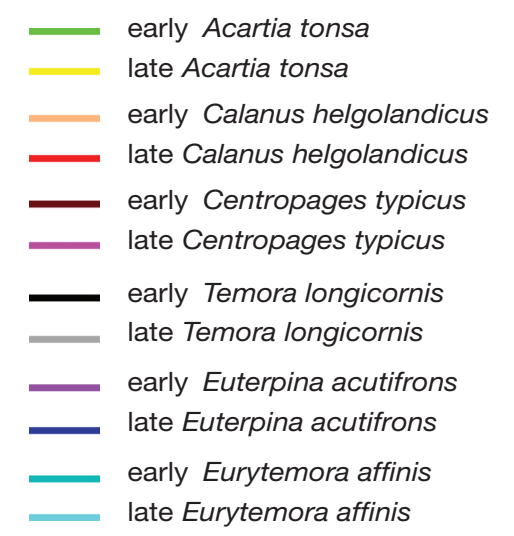

Fig. 1. Representative swimming trails of early and late stages of copepod nauplii. All trails are of equal temporal duration (16 s). No smoothing is applied to the data in the graph. The trail for small Eurytemora affinis is disproportionate in length due to convection in the aquarium (i.e. the nauplius moved faster in the sink direction). Data from Titelman \& Kiørboe (2003)

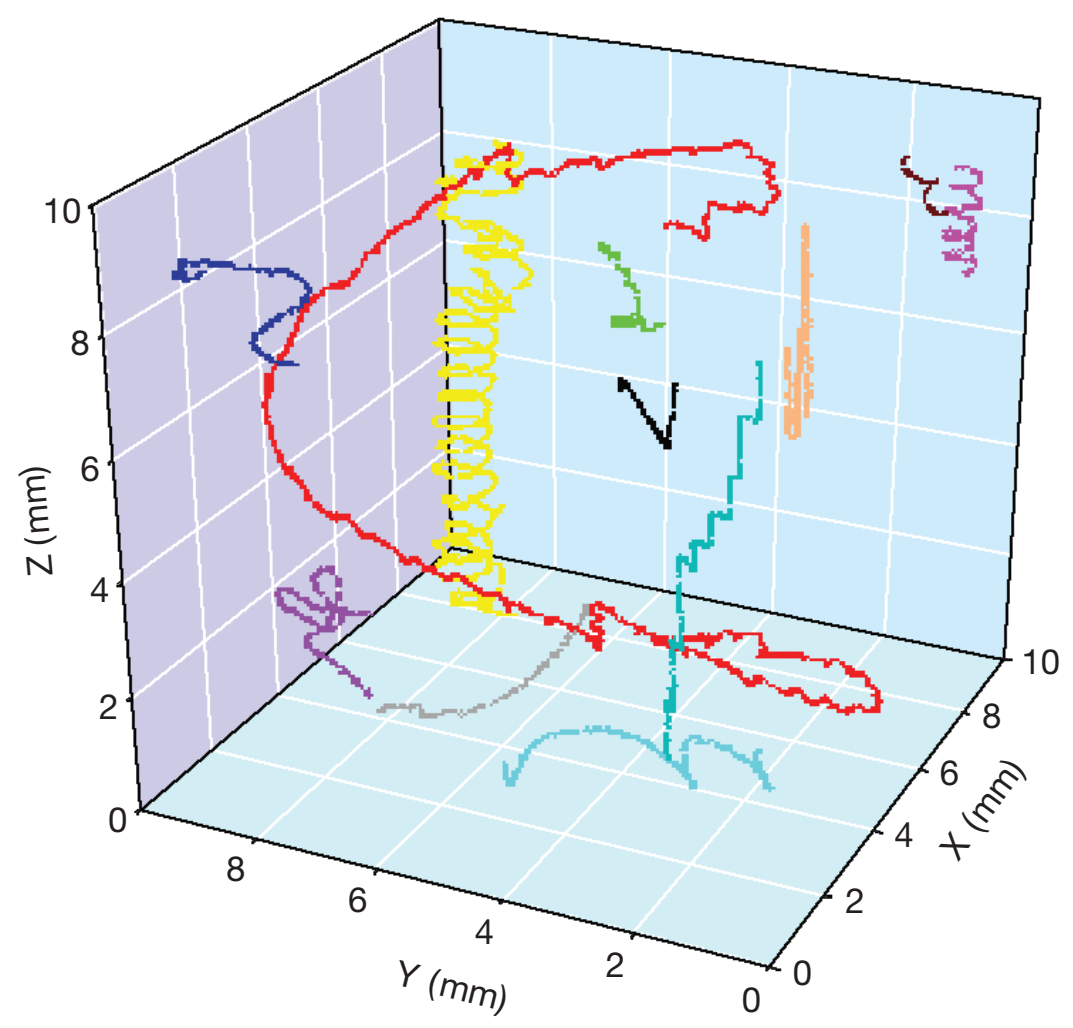


Table 2. Naupliar stages and sizes used, and flow rates applied in experiments. Size and stage were measured for 20 to 30 individuals per filming. The stage column shows the 2 most common stages with the more abundant one underlined. The percentage column shows the percentage contribution of the 2 dominant stages and that of the dominant one in parentheses. Lengths are total body lengths excluding caudal armature. $Q$ is the mean volume flow rate and $\mathrm{n}$ the number of escape events observed

\begin{tabular}{|c|c|c|c|c|c|c|}
\hline Species & $\begin{array}{l}\text { Nominal } \\
\text { group }\end{array}$ & $\begin{array}{l}\text { Nauplius } \\
\text { stage }\end{array}$ & $\%$ & $\begin{array}{c}\text { Length } \pm \text { SD } \\
(\mu \mathrm{m})\end{array}$ & $\begin{array}{l}\mathrm{Q} \pm \mathrm{SD} \\
\left(\mathrm{ml} \mathrm{s}^{-1}\right)\end{array}$ & $\mathrm{n}$ \\
\hline $\begin{array}{l}\text { Calanus } \\
\text { helqolandicus }\end{array}$ & $\begin{array}{l}\text { Early } \\
\text { Late }\end{array}$ & $\begin{array}{l}\text { I-II } \\
\text { IV-V }\end{array}$ & $\begin{array}{r}100(\underline{83}) \\
93(\underline{63})\end{array}$ & $\begin{array}{l}231 \pm 14 \\
553 \pm 54\end{array}$ & $\begin{array}{l}1.32 \pm 0.047 \\
1.38 \pm 0.015\end{array}$ & $\begin{array}{l}41 \\
19\end{array}$ \\
\hline $\begin{array}{l}\text { Centropages } \\
\text { typicus }\end{array}$ & $\begin{array}{l}\text { Early } \\
\text { Late }\end{array}$ & $\begin{array}{l}\text { I-II } \\
\underline{I V}-\mathrm{V}\end{array}$ & $100(\underline{60})$ & $\begin{array}{l}132 \pm 16 \\
225 \pm 33\end{array}$ & $\begin{array}{l}1.35 \pm 0.026 \\
1.40 \pm 0.006\end{array}$ & $\begin{array}{l}25 \\
77\end{array}$ \\
\hline $\begin{array}{l}\text { Eurytemora } \\
\text { affinis }\end{array}$ & $\begin{array}{l}\text { Early } \\
\text { Late }\end{array}$ & $\begin{array}{l}\mathrm{I}-\underline{\mathrm{II}} \\
\mathrm{IV}-\mathrm{V}\end{array}$ & $\begin{array}{r}100(\underline{67}) \\
73(\underline{60})\end{array}$ & $\begin{array}{l}132 \pm 11 \\
202 \pm 27\end{array}$ & $\begin{array}{l}1.22 \pm 0.032 \\
1.38 \pm 0.075\end{array}$ & $\begin{array}{l}78 \\
44\end{array}$ \\
\hline $\begin{array}{l}\text { Euterpina } \\
\text { acutifrons }\end{array}$ & $\begin{array}{l}\text { Early } \\
\text { Early } \\
\text { Late }\end{array}$ & $\begin{array}{l}\underline{I}-\mathrm{II} \\
\mathrm{I}-\mathrm{II} \\
\mathrm{IV}-\underline{\mathrm{V}}\end{array}$ & $\begin{array}{c}93(\underline{83}) \\
- \\
93(\underline{71})\end{array}$ & $\begin{array}{l}112 \pm 15 \\
112 \pm 12 \\
200 \pm 27\end{array}$ & $\begin{array}{l}0.89 \pm 0.01 \\
1.39 \pm 0.01 \\
1.34 \pm 0.01\end{array}$ & $\begin{array}{l}16 \\
10 \\
14\end{array}$ \\
\hline
\end{tabular}

\section{RESULTS}

\section{Signal detection}

Most species and stages of nauplii responded to the flow field by eliciting escape jumps at well-defined critical deformation rates, $\Delta^{*}$. The only exception was early Euterpina acutifrons, where only $46 \%$ responded. Estimates of groupspecific average $\Delta^{*}$ varied between 0.5 and $4.2 \mathrm{~s}^{-1}$ (Table 3 ). These $\Delta^{*}$ values correspond to signal strengths $\left(\mathrm{s}_{\Delta^{*}}\right)$ of 0.006 to $0.09 \mathrm{~cm} \mathrm{~s}^{-1}$ (Table 3 ). There are no consistent differences in $\Delta^{*}$ between early and later nauplii (Table 3 ).

When considered together, however, the sensitivity to hydrodynamic signals was related to the general motility behavior of the nauplii. Nauplii with a jump-

unidirectional rapid jumps in response to the flow, we considered only the first jump. Only jumps initiated in the hemisphere above the mouth of the pipette were included in the analyses, because the flow field below the tip is affected by the boundary layer along the pipette (cf. Kiørboe et al. 1999).

The critical deformation rate $\left(\Delta^{*}\right)$ required to induce a response was calculated as:

$$
\Delta^{*}=\frac{Q}{2 \pi r^{3}}
$$

where $Q$ is the volume flow rate $\left(\mathrm{ml} \mathrm{s}^{-1}\right)$ and $r$ the distance $(\mathrm{cm})$ from the mouth of the siphon where the nauplius initiates its escape (Kiørboe et al. 1999). The signal strength, $s_{\Delta^{*}},\left(\mathrm{~cm} \mathrm{~s}^{-1}\right)$ due to deformation is then:

$$
S_{\Delta^{*}}=\Delta^{*} \times a
$$

where $a$ is the equivalent radius of the nauplius, here approximated with half of the body length (Kiørboe et al. 1999).

We computed jump distance, speed and direction from the start and end position of each escape. However, the flow field influences the end point of the jump. We corrected for this distortion as described by Jakobsen (2001). Directions of flow-corrected escape jumps were expressed relative to the flow direction and relative to a horizontal plane (gravity). The radial symmetry of the flow causes all angles relative to the flow line to vary between 0 and $180^{\circ}$. We denoted angles $<90^{\circ}$ to be against the flow direction (i.e. away from the pipette) and angles $>90^{\circ}$ to be with the flow direction (i.e. towards the pipette). Similarly, we defined escape angles relative to a horizontal plane as varying between -90 and $+90^{\circ}$, where $0^{\circ}$ corresponds to jumping horizontally, $-90^{\circ}$ to jumping straight down and $+90^{\circ}$ to jumping straight up. sink behavior responded to lower fluid deformation rates than did nauplii, with a more continuous swimming behavior (Fig. 2). This difference increased with increasing animal size because the deformation rate required to elicit an escape generally increased with increasing size for swimming nauplii, but decreased for nauplii with a jump-sink motility (Fig. 2).

\section{Escape distance and speed}

Escape distance and jump speeds did not differ between the 2 motility types (Fig. 3, Table 4). The

Table 3. Critical deformation rates ( $\left.\Delta^{*}\right)$ (Eq. [2]) and threshold signal strengths due to critical deformation ( $\left.\mathrm{s}_{\Delta^{*}}\right)$ (Eq. [3]) estimated for the nauplii of 6 species of copepods. Data for $\Delta^{*}$ and $\mathrm{s}_{\Delta^{*}}$ are geometric means with $95 \%$ confidence limits in parenthesis. Size is total body length $\pm \mathrm{SD}$, excluding caudal armature. The younger stage groups are dominated by NI-II, except for Temora longicornis where stages NII-III dominated. Data for Acartia tonsa from Kiørboe et al. (1999), and for T.

\begin{tabular}{|c|c|c|c|c|}
\hline Species & $\begin{array}{l}\text { Stage } \\
\text { group }\end{array}$ & $\begin{array}{l}\Delta^{*} \\
\left(\mathrm{~s}^{-1}\right)\end{array}$ & $\begin{array}{c}\mathrm{S}_{\Delta^{*}} \\
\left(\mathrm{~cm} \mathrm{~s}^{-1}\right)\end{array}$ & $\begin{array}{l}\text { Size } \\
(\mu \mathrm{m})\end{array}$ \\
\hline $\begin{array}{l}\text { Calanus } \\
\text { helgolandicus }\end{array}$ & $\begin{array}{l}\text { Early } \\
\text { Late }\end{array}$ & $\begin{array}{l}0.52(0.67 ; 0.40) \\
3.24(5.26 ; 2.00)\end{array}$ & $\begin{array}{l}0.006 \\
0.090\end{array}$ & $\begin{array}{l}231 \pm 14 \\
553 \pm 54\end{array}$ \\
\hline $\begin{array}{l}\text { Centropages } \\
\text { typicus }\end{array}$ & $\begin{array}{l}\text { Early } \\
\text { Late }\end{array}$ & $\begin{array}{l}2.60(3.20 ; 2.11) \\
2.79(3.19 ; 2.44)\end{array}$ & $\begin{array}{l}0.017 \\
0.031\end{array}$ & $\begin{array}{l}132 \pm 16 \\
225 \pm 33\end{array}$ \\
\hline $\begin{array}{l}\text { Eurytemora } \\
\text { affinis }\end{array}$ & $\begin{array}{l}\text { Early } \\
\text { Late }\end{array}$ & $\begin{array}{l}1.88(2.19 ; 1.62) \\
2.65(3.49 ; 2.01)\end{array}$ & $\begin{array}{l}0.013 \\
0.027\end{array}$ & $\begin{array}{l}132 \pm 11 \\
202 \pm 27\end{array}$ \\
\hline $\begin{array}{l}\text { Euterpina } \\
\text { acutifrons }\end{array}$ & $\begin{array}{l}\text { Early } \\
\text { Late }\end{array}$ & $\begin{array}{l}4.25(5.58 ; 3.24) \\
1.92(2.72 ; 1.36)\end{array}$ & $\begin{array}{l}0.025 \\
0.019\end{array}$ & $\begin{array}{l}112 \pm 15 \\
200 \pm 27\end{array}$ \\
\hline $\begin{array}{c}\text { Acartia } \\
\text { tonsa }\end{array}$ & $\begin{array}{l}\text { Early } \\
\text { Late }\end{array}$ & $\begin{array}{l}2.49(2.08 ; 2.97) \\
1.19(0.85 ; 1.66)\end{array}$ & $\begin{array}{l}0.015 \\
0.015\end{array}$ & $\begin{array}{l}119 \pm 11 \\
225 \pm 55\end{array}$ \\
\hline $\begin{array}{l}\text { Temora } \\
\text { longicornis }\end{array}$ & $\begin{array}{l}\text { Early } \\
\text { Late }\end{array}$ & $\begin{array}{l}2.78(2.45 ; 3.15) \\
3.96(3.31 ; 4.73)\end{array}$ & $\begin{array}{l}0.024 \\
0.059\end{array}$ & $\begin{array}{l}169 \pm 27 \\
295 \pm 43\end{array}$ \\
\hline
\end{tabular}
longicornis from Titelman (2001) 


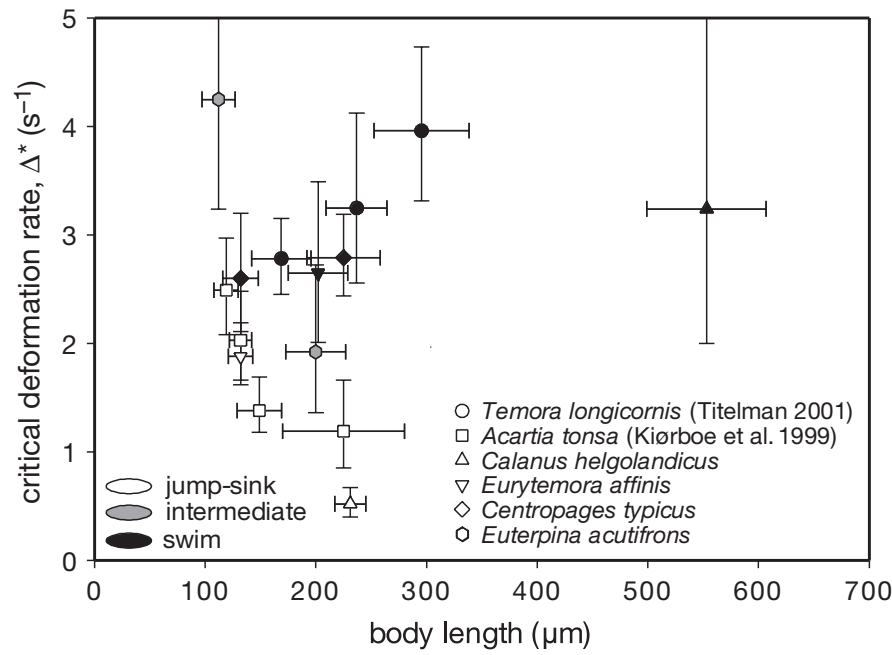

Fig. 2. Deformation rate at point of initial escape for copepod nauplii. Critical deformation rates $\left(\Delta^{*}\right)$ are geometric means with error bars representing 95\% confidence limits, while sizes are arithmetic means \pm SD (Table 3 ). Symbol shapes represent species, while the fill color indicates the type of spontaneous motility (Table 2)

range of average escape distance was $\sim 5$ to 20 body lengths, with large intra-group variation (Fig. 3A, Table 4). Absolute escape distances increased with age in Calanus helgolandicus and Euterpina acutifrons, but not in Centropages typicus and Eurytemora affinis (Table 4). Absolute escape speeds also increased with age in most species (Table 4). Average speeds were $\sim 60$ to 130 body lengths $\mathrm{s}^{-1}$ with large variation within groups and differences in size scaling between species (Fig. 3B). Escape velocities reported here are conservative because of the time step (0.04 s) used in digitizing. Generally, neither the escape length nor the speed was related to the $\Delta^{*}$ (Fig. 4).

\section{Jump angles}

Most of the species and stages oriented their escape jumps upwards and also away from the flow (Fig. 5, Table 4). This result suggests that many nauplii can assess directionality of the signal and respond accordingly. There was no difference in this capability between motility types.

\section{DISCUSSION}

We have quantified motility (Titelman \& Kiørboe 2003) and escaperelated behavior (this study) of several
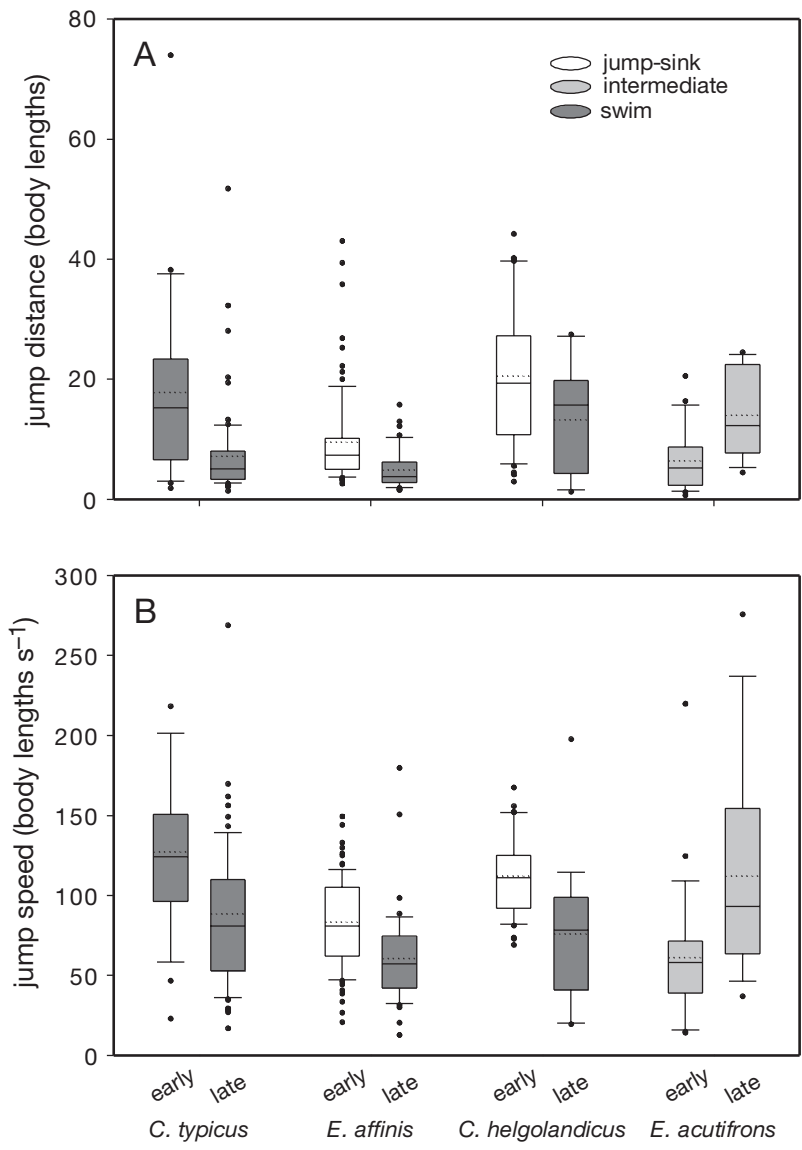

Fig. 3. Escape jumps. (A) Specific distance, (B) speed. Boxes indicate the 25 to 75 percentiles, solid lines the median values, whiskers the 10th and 90th percentiles, dotted lines the mean values, and dots the outliers. Fill color represents the type of spontaneous motility (Table 2). Boxes are based on number of observations in Table 2

copepod nauplii with the purpose of examining various behavioral strategies for predator avoidance. In the following, we pursue this goal by applying simple hydrodynamic models to our observations (e.g. Kiørboe \&

Table 4. Escape jump length, speed and angles relative to horizontal and to flow direction ( $\theta_{\text {horiz, }}$ and $\theta_{\text {flow, }}$ respectively), and length and speed of spontaneous jumps for nauplii of 4 species of copepods. Values are mean \pm SD. For definition of jump angles see 'Methods'

\begin{tabular}{|lccccc|}
\hline Species & $\begin{array}{c}\text { Stage } \\
\text { group }\end{array}$ & $\begin{array}{c}\text { Length } \\
(\mathrm{cm})\end{array}$ & $\begin{array}{c}\text { Speed } \\
\left(\mathrm{cm} \mathrm{s}^{-1}\right)\end{array}$ & $\begin{array}{c}\theta_{\text {horiz. }} \\
\left({ }^{\circ}\right)\end{array}$ & $\begin{array}{c}\theta_{\text {flow }} \\
\left({ }^{\circ}\right)\end{array}$ \\
\hline Calanus & Early & $0.474 \pm 0.264$ & $2.60 \pm 0.57$ & $64.0 \pm 17.4$ & $36.6 \pm 24.9$ \\
helgolandicus & Late & $0.732 \pm 0.504$ & $4.20 \pm 2.36$ & $50.2 \pm 25.1$ & $48.5 \pm 28.1$ \\
$\begin{array}{c}\text { Centropages } \\
\text { typicus }\end{array}$ & Early & $0.235 \pm 0.205$ & $1.68 \pm 0.77$ & $17.5 \pm 35.9$ & $63.6 \pm 35.7$ \\
$\begin{array}{c}\text { Eurytemora } \\
\text { affinis }\end{array}$ & Late & $0.161 \pm 0.164$ & $1.99 \pm 1.15$ & $30.7 \pm 44.0$ & $61.0 \pm 39.7$ \\
$\begin{array}{c}\text { Euterpina } \\
\text { acutifrons }\end{array}$ & Late & $0.125 \pm 0.101$ & $1.10 \pm 0.36$ & $24.0 \pm 38.9$ & $69.9 \pm 36.6$ \\
& Early & $0.099 \pm 0.063$ & $0.67 \pm 0.22$ & $8.2 \pm 26.5$ & $82.6 \pm 26.1$ \\
\hline
\end{tabular}



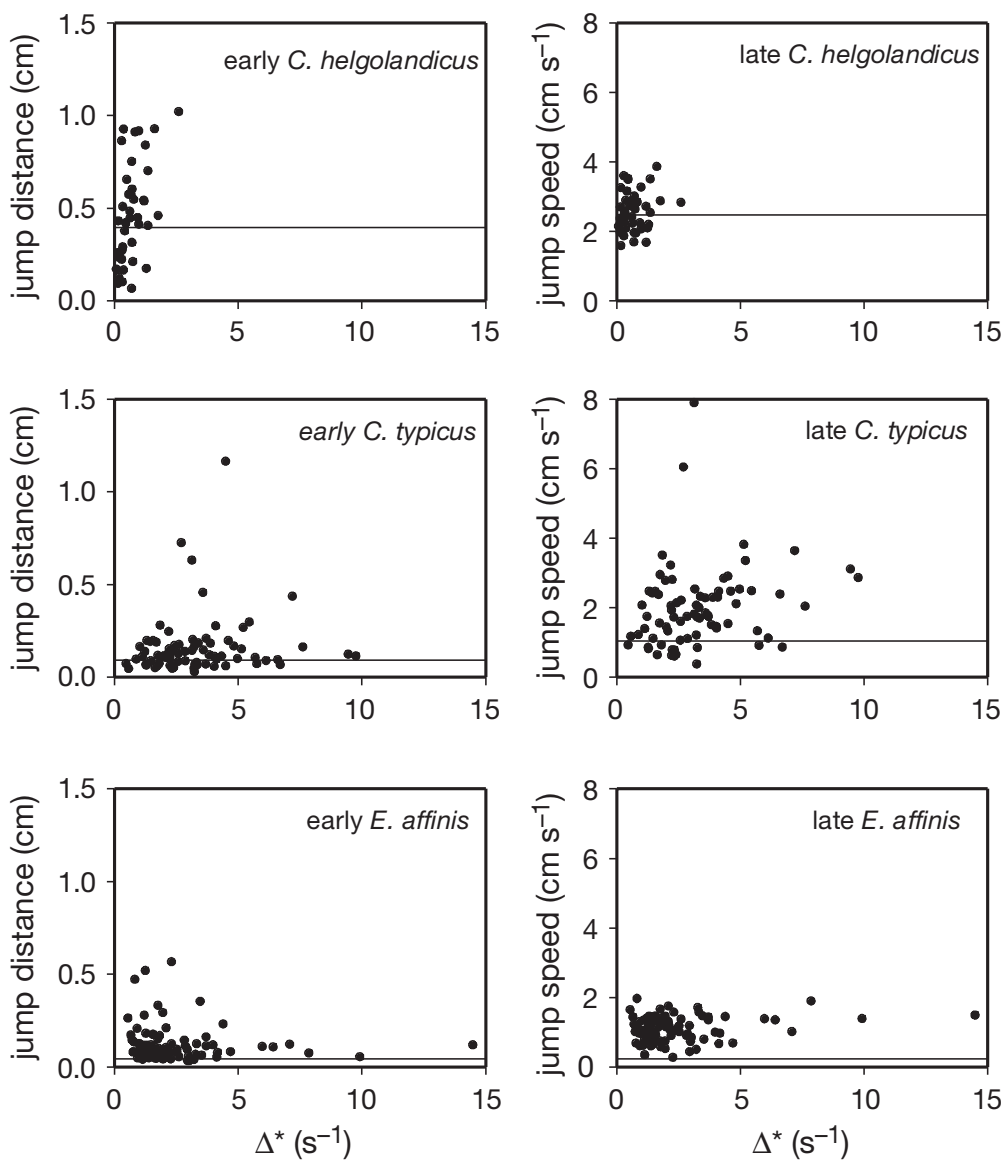

Fig. 4. Examples of $\Delta^{*}$ versus jump speed and $\Delta^{*}$ versus jump distance. The horizontal lines represent the average spontaneous jump length or speed (Table 4 )

Visser 1999, Svensen \& Kiørboe 2000, Visser 2001). We first examine how different prey motility patterns affect their detectability ( $R$ in Eq. 1 ) and next, consider the implications of prey motility for volume encounter rates with ambush and cruising predators ( $\beta$ in Eq. 1). We then examine prey detection and escape capabilities in various predator-prey interactions ( $p$ in Eq. 1), allowing us to assess the overall predation risk for various behavioral strategies. We finally compare our model predictions with measured copepod predation rates on nauplii (e.g. Landry 1980, Daan et al. 1988, Sell et al. 2001).

Essentially, nauplii can be divided into 2 motility types: viz., a jump-sink type that hangs motionless in the water while slowly sinking and occasionally interrupts the sinking by a brief hop, and a type with more or less constant swimming (cruising). The fraction of time spent actively moving (swimming or hopping) and movement velocities vary dramatically among the different nauplii (Table 5), as do the resulting swim tracks (Fig. 1). In the following, for simplicity, we mostly consider a generic $200 \mu \mathrm{m}$ long nauplius, which moves in either of the 2 styles. We assume representative velocities, jump frequencies, jump durations, time budgets and detectability distances (Table 6). Further, we assume interactions with a 5-fold larger copepod predator using either a feeding current, an ambush or a cruising strategy to encounter prey.

\section{Prey detectability $\left(\boldsymbol{R}_{\text {pred }}\right)$}

The hydrodynamic signal that a prey generates and thus, the distance at which it can be detected by a copepod predator $\left(R_{\text {pred }}\right)$, depends on prey size, velocity and propulsion modus (e.g. Gallager 1993). The fluid motion generated by a sinking nauplius may be described as a creeping Stokes' flow around a sphere (Kiørboe et al. 1999), while a selfpropelled nauplius is better approximated by a dipole model (Svensen \& Kiørboe 2000, Visser 2001). In either case, the generated fluid velocity declines with distance from the moving nauplius. We assume that a copepod detects a smaller prey at the distance where the fluid velocity generated by the prey equals the threshold velocity required to elicit an attack $\left(u^{*}\right)$ (Kiørboe \& Visser 1999, Kiørboe et al. 1999). Hence, a predatory copepod detects a sinking nauplius at a distance:

$$
R_{\text {pred-sink }} \approx \frac{V_{\text {sink }} a}{u^{*}}
$$

where $v_{\text {sink }}$ is the nauplius sink velocity and $a$ its radius (Svensen \& Kiørboe 2000). (See Table 1 for definition of symbols.) For an actively moving nauplius:

$$
R_{\text {pred-move }}=\left|\frac{3 \pi v_{\text {move }} \mathrm{a}^{2}(1+3 \cos [2 \theta])}{2 u^{*}}\right|^{0.5}
$$

where $v_{\text {move }}$ is the swimming or jumping velocity of the nauplius and $\theta$ the angle away from the nauplius (Svensen \& Kiørboe 2000).

Estimates of $u^{*}$ for various copepods vary between $\sim 10^{-3}$ and $10^{-1} \mathrm{~cm} \mathrm{~s}^{-1}$ (Kiørboe \& Visser 1999, Lenz \& Hartline 1999, Titelman 2001). If we assume that $u^{*}=$ $0.01 \mathrm{~cm} \mathrm{~s}^{-1}$, our generic nauplius is detectable at $\sim 0.02$, $\sim 0.08$ and $\sim 0.3 \mathrm{~cm}$ (at $\theta=\pi / 2$ ) when sinking, swimming and jumping, respectively. This prediction is consistent with the observation that Centropages typicus copepods detect jumping Acartia tonsa nauplii farther away than it detects swimming Temora longicornis nauplii (Titelman 2001). Sinking nauplii are almost hydrodynamically undetectable since the $R_{\text {pred }}$ approaches their own size (Fig. 6). Nauplii may thus be detected by a predator at very different distances depending on 

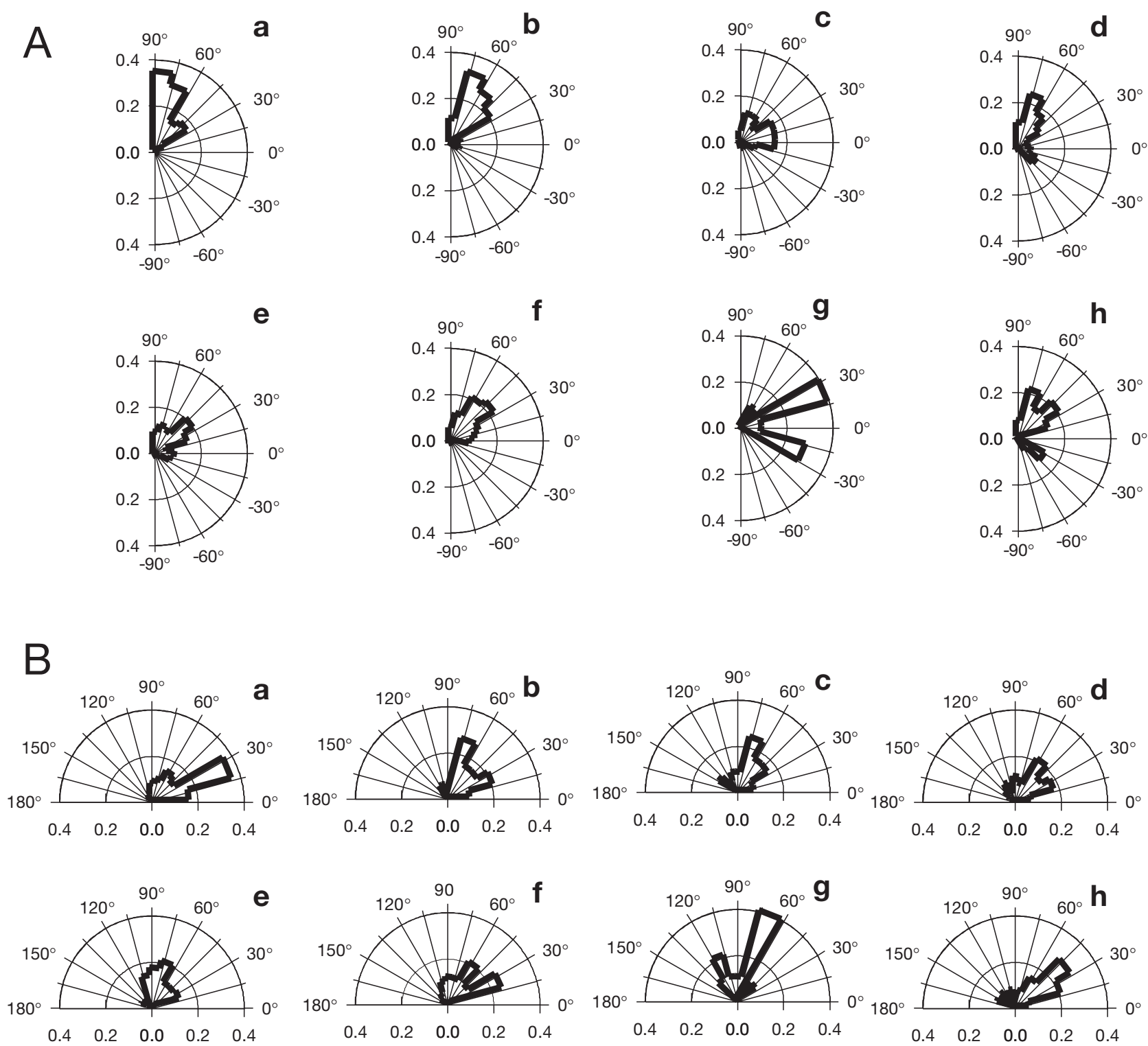

Fig. 5. (A) Naupliar escape jump angles relative to a horizontal plane and (B) a flow line for (a) early Calanus helgolandicus, (b) late Calanus helgolandicus, (c) early Centropages typicus, (d) late C. typicus, (e) early Eurytemora affinis, (f) late E. affinis, (g) early Euterpina acutifrons and (h) late E. acutifrons. All distributions are relative frequencies based on the number of observations in Table 2. (A) Escape angles vary between -90 and $+90^{\circ}$, where $-90^{\circ}$ corresponds to jumping straight down and $+90^{\circ}$ to jumping straight up. (B) Angles vary between 0 and $180^{\circ}$, where angles $<90^{\circ}$ are against the flow direction (i.e. away from the pipette) and angles $>90^{\circ}$ are with the flow direction (i.e. towards the pipette). For E. acutifrons only high flow observations are plotted

their motility patterns (Fig. 6). To evaluate the rate at which predators are encountered, we need to integrate our behavior-specific estimates of $R_{\text {pred }}$ in estimates of encounter volume rates.

\section{Encounter volume rates $(\beta)$}

Encounter volume rate formulations represent timeintegrated exposure to predation risk. Estimates are useful for relative comparisons between behaviors and/or motility types, while absolute values should be interpreted with a pinch of salt. For simplicity, we assume a spherical predator in a generic volume encounter rate ( $\beta$ ) expression (cf. Kiørboe \& Saiz 1995):

$$
\beta_{\mathrm{tot}}=\sum_{i} t_{i}\left(\pi R_{\mathrm{i}}^{2} \Delta v_{i}\right)
$$

where $R=\left(R_{\text {pred }}+c\right)$ and $c$ is the radius of the predator, subscripts denote the behavior (swimming, jumping or 
Table 5. Summary of the spontaneous motility of copepod nauplii in still water. Generalized motility type, time spent moving $\left(t_{\text {move }}\right)$, average move and sinking speeds ( $V_{\text {move }}$ and $V_{\text {sink }}$ ), and body length for early and late stages of different species. For nauplii where continuous swimming dominates, occasional spontaneous jumps are not considered here. Data are mean values from Titelman \& Kiørboe (2003), where details on variation, other motility parameters and stage distributions can also be found

\begin{tabular}{|lcccccc|}
\hline Species & $\begin{array}{c}\text { Stage } \\
\text { group }\end{array}$ & $\begin{array}{c}\text { Motility } \\
\text { type }\end{array}$ & $\begin{array}{c}t_{\text {move }} \\
(\%)\end{array}$ & $\begin{array}{c}V_{\text {move }} \\
\left(\mathrm{mm} \mathrm{s}^{-1}\right)\end{array}$ & $\begin{array}{c}V_{\text {sink }} \\
\left(\mathrm{mm} \mathrm{s}^{-1}\right)\end{array}$ & $\begin{array}{c}\text { Length } \\
(\mu \mathrm{m})\end{array}$ \\
\hline Acartia & Early & Jump-sink & 13.2 & 3.9 & 0.13 & 118 \\
tonsa & Late & Jump-sink & 35.1 & 10.38 & 0.31 & 229 \\
Centropages & Early & Swim & 94.8 & 0.33 & 0.05 & 132 \\
typicus & Late & Swim & 98.0 & 0.72 & 0.14 & 225 \\
Calanus & Early & Jump-sink & 2.6 & 24.8 & 0.26 & 231 \\
helgolandicus & Late & Swim & 84.4 & 3.76 & 0.76 & 553 \\
Eurytemora & Early & Jump-sink & 8.4 & 2.27 & 0.10 & 132 \\
affinis & Late & Swim & 38.7 & 1.64 & 0.18 & 202 \\
Temora & Early & Jump-sink & 1.2 & 11.03 & 0.09 & 138 \\
longicornis & Late & Swim & 83.3 & 0.57 & 0.24 & 308 \\
Euterpina & Early & Swim & 79.9 & 0.98 & 0.09 & 112 \\
acutifrons & Late & Swim & 67.9 & 1.08 & 0.26 & 200 \\
\hline
\end{tabular}

sinking) in question, and $t$ is the fraction of time spent in that behavior. Summing the $3 \beta_{i}$ yields the total volume encounter rate $\left(\beta_{\text {tot }}\right)$.

Behavior specific $R$ were estimated using Eqs. (4) \& (5). $\Delta v_{i}$ is computed assuming random arrival directions of prey to the predator (Evans 1989):

$$
\Delta v_{i}=\left(u^{2}+v_{i}^{2}\right)^{0.5}
$$

except for cases when both predator and prey are sinking; then:

$$
\Delta v_{i}=\left|u-v_{i}\right|
$$

where $u$ and $v$ are behavior-specific predator and prey velocities.

The so computed encounter volume rates varied dramatically with prey and somewhat with predator behavior (Fig. 7). For an ambush predator sinking slowly through the water $\beta_{\text {tot }}$ spans 3 orders of magnitudes depending on naupliar behavior (Fig. 7A). Low frequency jump-sink nauplii (e.g. Oithona) generate the smallest $\beta_{\text {tot, }}$ while high frequency jumpers (e.g. Acartia tonsa) are at the highest risk (Fig. 7A). With a cruising predator, $\beta_{\text {tot }}$ becomes slightly higher for all motility types, but the general pattern remains similar to the ambush case (Fig. 7). For the medium frequency jump-sink types (e.g. early Calanus), $\beta_{\text {tot }}$ resembles that of cruising nauplii, but is still only $\sim^{1 / 10}$ of the frequently jumping nauplii (Fig. 7). The comparatively minute relative time spent actively moving dominates the contribution to $\beta_{\text {tot }}$ for jump-sink nauplii once jump frequency exceeds $2 \mathrm{~min}^{-1}$ (Fig. 7A,B,C).

Cruising nauplii move either in helical or straighter paths (Fig. 1). For looping prey, the velocity relevant for $\Delta v$ is the speed along the helical axis $\left(V_{\text {transport }}\right)$ rather than the measured velocity ( $V_{\text {move }}$ ) (Table 7) (Svensen \& Kiørboe 2000). Because $V_{\text {transport }}<V_{\text {move }}$ a helical path yields a lower $\Delta v$ and thus, reduces $\beta$ when compared to a straighter trail. A steeper path enhances this effect (Svensen \& Kiørboe 2000). We estimate the benefit of prey looping and find that looping only modestly affects $\beta$ (Fig. 7). Effects of helical swimming trails and potential plasticity in motility behavior, for example in response to food (van Duren \& Videler 1995), both appear modest when compared to the dramatic effect of overall motility type (Fig. 7). Frequent jumpers experience a risk of encountering a predator that is orders of magnitude higher than that for swimmers. Is this higher predator encounter rate compensated for by a more efficient escape behavior?

\section{Detecting and escaping predators}

Jump-sink nauplii are better at detecting hydrodynamic signals than swimmers, and this relative difference grows with naupliar size (Fig. 2). Is this difference

Table 6. Summary of behavioral parameters of generic 200 $\mu \mathrm{m}(a=0.01 \mathrm{~cm})$ long nauplii with different motility used for calculations of detectability $\left(R_{\text {pred }}\right)$ and volume encounter rates $(\beta)$. Jump frequencies $\left(f_{\text {jump }}\right)$ are representative of cyclopoid and poecilostomatoid nauplii (low) (Paffenhöfer 1993, Paffenhöfer et al. 1996), and Acartia tonsa (high) (Table 2). Fraction of time spent actively moving $\left(t_{\text {move }}\right)$ was calculated assuming a jump duration of $0.1 \mathrm{~s}$ for jump-sink types (Titelman \& Kiørboe 2003). Velocities $\left(V_{\mathrm{i}}\right)$ and critical deformation rates $\left(\Delta^{*}\right)$ are representative of nauplii in this study (cf. Tables $2,4 \& 7)$. Unless otherwise noted, we assumed a predator with $u^{*}=0.01 \mathrm{~cm} \mathrm{~s}^{-1}, u_{\text {sink }}=0.1 \mathrm{~cm} \mathrm{~s}^{-1}, u_{\text {cruise }}=0.3 \mathrm{~cm} \mathrm{~s}^{-1}$ and $c=0.05 \mathrm{~cm}$ in all calculations

\begin{tabular}{|lcccc|}
\hline \multirow{2}{*}{ Parameter } & \multicolumn{4}{c|}{ Motility type } \\
& Jump-sink & \multicolumn{2}{c|}{ Swim } \\
& Low & High & Straight & Loop \\
\hline$f_{\text {jump }}\left(\mathrm{s}^{-1}\right)$ & 0.0167 & 3 & - & - \\
$t_{\text {move }}(\%)$ & 0.167 & 30 & 100 & 100 \\
$V_{\text {sink }}\left(\mathrm{Cm} \mathrm{s}^{-1}\right)$ & 0.02 & 0.02 & 0.02 & 0.02 \\
$V_{\text {swim }}\left(\mathrm{Cm} \mathrm{s}^{-1}\right)$ & - & - & 0.07 & 0.07 \\
$V_{\text {jump }}\left(\mathrm{Cm} \mathrm{s}^{-1}\right)$ & 1 & 1 & - & - \\
$V_{\text {move }}\left(\mathrm{cm} \mathrm{s}^{-1}\right)$ & 1 & 1 & 0.07 & 0.07 \\
$V_{\text {transport }}\left(\mathrm{cm} \mathrm{s}^{-1}\right)$ & - & - & - & 0.01 \\
$R_{\text {pred-sink }}(\mathrm{cm})$ & 0.020 & 0.020 & 0.020 & 0.020 \\
$R_{\text {pred-move }}(\mathrm{cm})$ & 0.31 & 0.31 & 0.081 & 0.081 \\
$\Delta^{*}\left(\mathrm{~s}^{-1}\right)$ & 1 & 1 & 4 & 4 \\
\hline
\end{tabular}




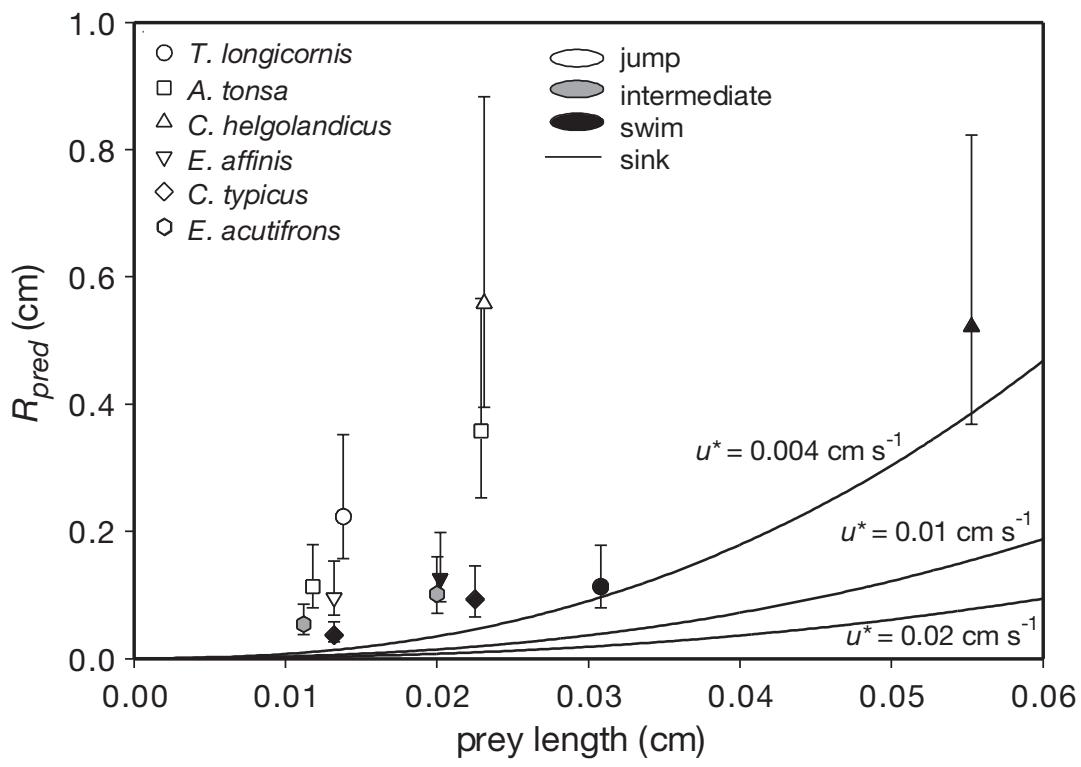

Fig. 6. Computed detectability $\left(R_{\text {pred }}\right)$ of the nauplii in Table 5 when sinking ( $R_{\text {pred-sink }}$ lines) or moving actively ( $R_{\text {pred-mover }}$ symbols) calculated from Eqs. (4) $\&$ (5). Symbols indicate values of $R_{\text {pred-move, }}$ assuming that $u^{*}=0.01 \mathrm{~cm} \mathrm{~s}^{-1}$. Symbols represent species and fill color the general motility type. Error bars denote the range for $u^{*}$ between 0.004 and $0.02 \mathrm{~cm} \mathrm{~s}^{-1}$ (Oithona similis $0.004 \mathrm{~cm} \mathrm{~s}^{-1}$, Kiørboe \& Visser 1999; Undinula vulgaris 0.004 to $0.009 \mathrm{~cm} \mathrm{~s}^{-1}$, Lenz \& Hartline 1999; Centropages typicus $0.02 \mathrm{~cm} \mathrm{~s}^{-1}$, Titelman 2001). Solid lines indicate $R_{\text {pred-sink }}$ for nauplii of various sizes, for $u^{*}=0.004, u^{*}=0.01$ and $u^{*}=0.02 \mathrm{~cm} \mathrm{~s}^{-1}$. $R_{\text {pred-sink }}$ calculated assuming that $v_{\text {sink }}=1.68 L^{1.38}$, where $v_{\text {sink }}$ is sinking speed $\left(\mathrm{mm} \mathrm{s}^{-1}\right)$ and $L$ is body length $(\mathrm{mm})$ (Titelman \& Kiørboe 2003) where $U$ is the maximum feeding current velocity. Straight in front of the copepod, the feeding current velocity at a distance $r\left(u_{\mathrm{r}}\right)$ is (Kiørboe \& Visser 1999):

$$
u_{r}=-U\left(\frac{3 c}{2 r}-\frac{c^{3}}{2 r^{3}}\right)
$$

For filtering copepods, $C \approx 2 / 3$ cephalothorax width (Kiørboe et al. 1999). By fitting literature data of lengths $(1, \mathrm{~cm})$, width $(W, \mathrm{~cm})$ and $U\left(\mathrm{~cm} \mathrm{~s}^{-1}\right)$, and assuming $C$ as above, we arrived at the following relationships: $w=0.3641-0.00155$, $\mathrm{R}^{2}=0.99 ; \quad U=7.0271^{1.156}, \mathrm{R}^{2}=0.87$ (data compiled in Kiørboe et al. 1999, their Table 6). We used these relationships and Eqs. (9) \& (10) to predict the feeding current velocity at the point of detection (Fig. 8). Observed escape speeds substantially exceed computed feeding current velocities at the point of detection and escape, suggesting that nauplii have a high likelihood of escaping filtering copepods (Fig. 8). This calculation accords with the observation that several species of nauplii detect and respond by escape jumps in flow fields generated by 2 Centropages species (Tiselius \& Jons- sufficiently large to generate a relative benefit for the jump-sink types in terms of escape from a predator? Below we examine the value of detection and escape abilities of nauplii in interactions with filtering and ambush-feeding predators.

\section{Filtering predator}

The peak deformation rate generated in a copepod's feeding current varies relatively little between species, 4 to $17 \mathrm{~s}^{-1}$ (estimated by Kiørboe et al. 1999), and is thus, generally higher than the deformation rates required to elicit escape in nauplii (Fig. 2). This observation implies that nauplii easily detect such flows and the question then becomes whether naupliar escape speeds exceed the feeding current velocity at the point of detection.

Applying the 'spherical pump model' of Kiørboe \& Visser (1999), we estimate that a nauplius entrained in a feeding current will detect the fluid disturbance at a distance $R_{\text {naup }}$ :

$$
R_{\text {naup }}=c \sqrt{\frac{3 U}{4 C \Delta^{*}}\left(1+\sqrt{1-\frac{8 C \Delta^{*}}{3 C}}\right)} \text { for } \Delta^{*} \leq \frac{3 U}{8 C}
$$
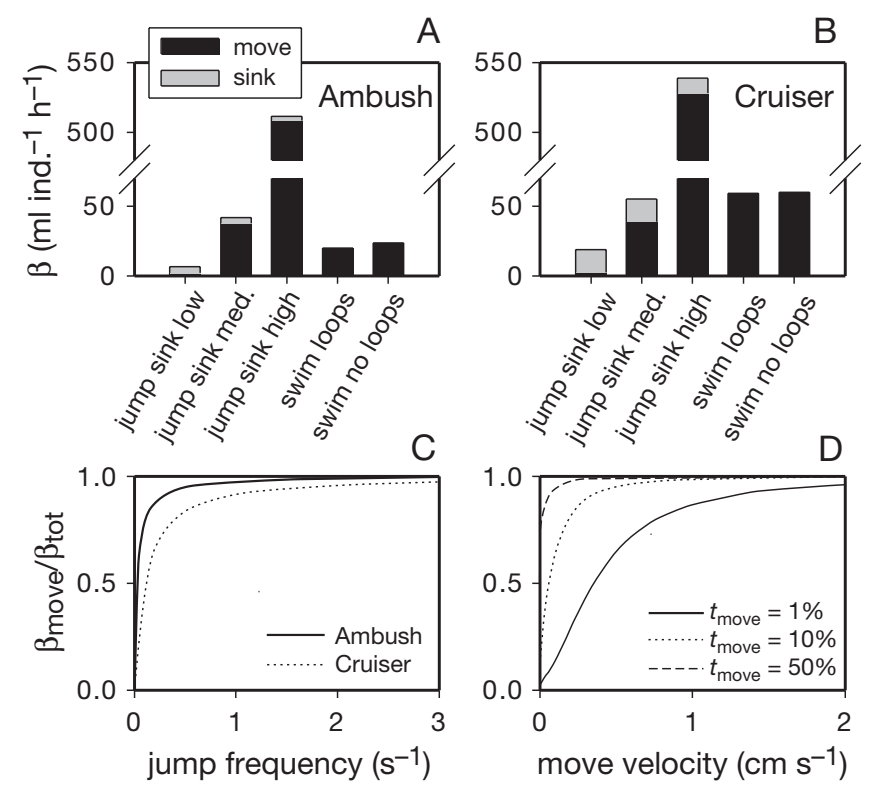

Fig. 7. Predator volume encounter rates $(\beta)$. $(A, B)$ Estimation of $\beta_{\text {sink }}$ and $\beta_{\text {move }}$ of generic nauplii (Table 6) with ambush (A) and cruising predators (B). (C) Fraction of $\beta_{\text {tot }}$ resulting from jumping behavior for jump-sink type of nauplii. (D) Fraction of $\beta_{\text {tot }}$ stemming from active motility as a function of $V_{\text {move }}$ for various time budgets. Input parameters in Table 6 
Table 7. Characteristics of helical motility trails in nauplii of 2 species of copepods, measured from tracks reported in Titelman \& Kiørboe 2003. Data are average \pm SD. $f_{\text {loop }}$ is the loop frequency, $\varnothing$ is the diameter of a loop, $A$ is the amplitude of the helix and $v_{\text {transport }}$ is the speed along the helical axes. $\mathrm{n}$ is 4 to 5. Sizes and stages in Table 2

\begin{tabular}{|lccccc|}
\hline Species & $\begin{array}{c}\text { Stage } \\
\text { group }\end{array}$ & $\begin{array}{c}f_{\text {loop }} \\
\left(\# \mathrm{~s}^{-1}\right)\end{array}$ & $\begin{array}{c}\varnothing \\
(\mathrm{mm})\end{array}$ & $\begin{array}{c}A \\
(\mathrm{~mm})\end{array}$ & $\begin{array}{c}V_{\text {transport }} \\
\left(\mathrm{mm} \mathrm{s}^{-1}\right)\end{array}$ \\
\hline Acartia tonsa & Early & $1.27 \pm 0.43$ & $0.73 \pm 0.24$ & $0.34 \pm 0.07$ & $0.43 \pm 0.16$ \\
Centropages typicus & Late & $0.13 \pm 0.02$ & $0.36 \pm 0.04$ & $0.65 \pm 0.09$ & $0.079 \pm 0.002$ \\
Centropages typicus & Early & $0.54 \pm 0.16$ & $0.44 \pm 0.01$ & $0.23 \pm 0.05$ & $0.12 \pm 0.05$ \\
\hline
\end{tabular}

son 1990) and by Temora longicornis (Yen \& Fields 1992). Although the more sensitive jump-sink types may respond farther away than continuous swimmers, the model thus predicts no immediate relative benefit in terms of escape from this type of predator.

\section{Ambush predator}

For a nauplius to detect a sinking ambush predator, the predator needs to sink faster than $U_{c r}$ (Kiørboe \& Visser 1999).

$$
U_{c r}=\frac{8 c \Delta^{*}}{3}
$$

Computed $U_{c r}$ of typical copepod predators ( $C$ : 0.025 to $0.05 \mathrm{~cm}$ ) are $\sim 0.03$ to 0.07 and $\sim 0.3$ to $0.5 \mathrm{~cm} \mathrm{~s}^{-1}$ for prey with $\Delta^{*}$ of 0.5 and $4 \mathrm{~s}^{-1}$. Typical sinking speeds of copepods are around $0.1 \mathrm{~cm} \mathrm{~s}^{-1}$ (Tiselius \& Jonsson 1990). Thus, while a cruising nauplius (high $\Delta^{*}$ ) has little chance of detecting a sinking predator and actually risks bumping into it, a jump-sink type is much better off. The different scaling of $\Delta^{*}$ with size for the 2 motility types (Fig. 2) implies that the relative benefit for the jump-sink type is low for the early small nauplii, but increases with naupliar size. In conclusion then, hydrodynamically sensitive jump-sink nauplii apparently have an actual escape advantage that compensates for their high 'visibility' when compared to the less sensitive cruising nauplii.

\section{Predation rates and behavioral strategies}

Copepod feeding rates on nauplii compiled from the literature (Table 8) along with video observations (Titelman 2001) agree with the predicted relative advantage of jump-sink types over cruising types in interactions with ambush feeding copepods. The prediction that both motility types would easily detect and escape flows of filtering predators (Fig. 8) is, however, not supported by observations.
Clearance measurements reveal that filtering Temora spp. copepods do catch nauplii, albeit at rates that are slightly lower than those of the ambush-feeding Centropages spp. of similar size (Table 8). Clearance data suggest that jump-sink nauplii may be at a relative advantage also in interactions with filtering predators (Table 8). This implies that this motility type is generally able to compensate for its noisy behavior and high predator encounter rates in interactions with copepod predators of various foraging strategies.

The discrepancy between the observations and predictions regarding the response of nauplii to filtering predators suggest that some components of the predator-prey interaction are still unresolved, and that our description of the escape event is incomplete. For

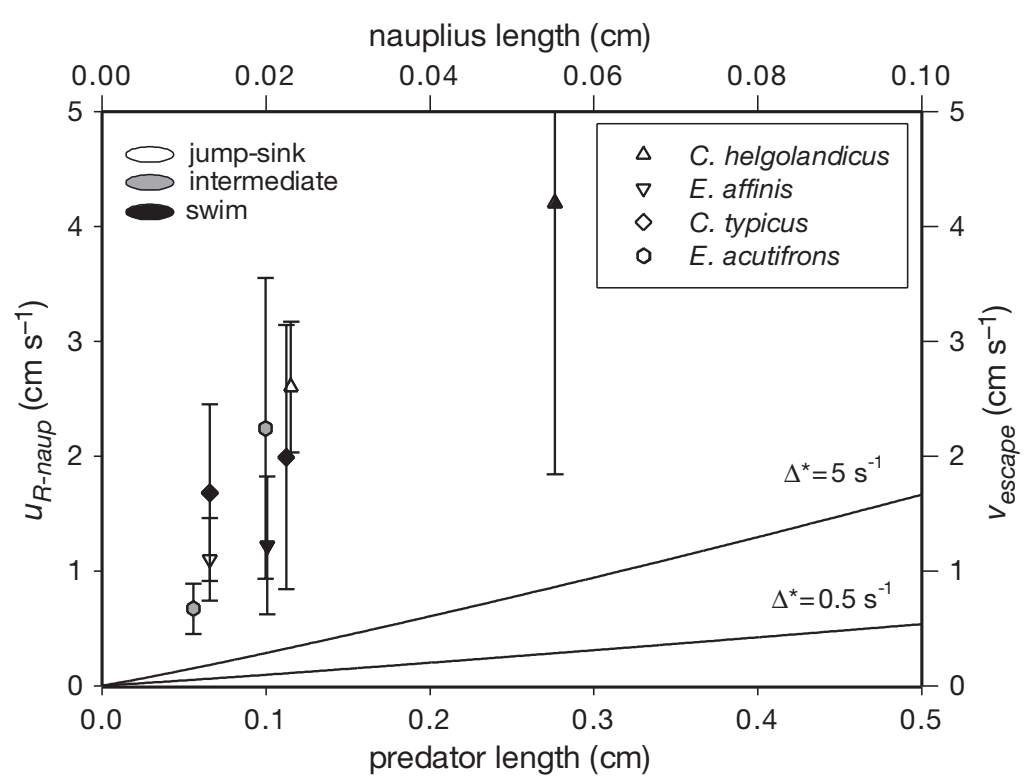

Fig. 8. Interactions between nauplii and feeding current-generating copepods. Lines indicate the predator flow field velocity at the point of nauplius detection ( $u_{\mathrm{R} \text {-naup }}$ left $y$-axis) for prey with $\Delta^{*}=0.5$ and $5 \mathrm{~s}^{-1}$ entrained in the flow fields of filtering copepods of different size (bottom $x$-axis). Measured nauplii escape velocities ( $v_{\text {escaper }}$ right $y$-axis) \pm SD plotted for comparison at a predator: prey size ratio of 5 (prey length, top $x$-axis). Symbol types represent species, while fill color represents general motility. See 'Discussion' for details on 'spherical pump model' (Kiørboe \& Visser 1999), and assumptions for calculations 
Table 8. Clearance rates of similarly sized copepods feeding on similarly sized nauplii that have different behavioral strategies. Temora is considered to feed using a feeding current, while Centropages can switch behavior between ambush and suspension feeding. We assume Centropages to have an ambush strategy when feeding on nauplii

\begin{tabular}{|c|c|c|c|c|c|c|}
\hline Predator & Prey species & Stage & $\begin{array}{l}\text { Length } \\
(\mu \mathrm{m})\end{array}$ & Behavior & $\begin{array}{c}\text { Clearance } \\
\left(\mathrm{ml} \text { ind }^{-1} \mathrm{~d}^{-1}\right)\end{array}$ & Reference \\
\hline \multicolumn{7}{|l|}{ Ambush } \\
\hline Centropages typicus & Acartia tonsa & NIV-VI & 216 & Jump-sink & 146 & Titelman (2001) \\
\hline Centropages hamatus & Acartia spp. & - & - & Jump-sink & 97 & Conley \& Turner (1985) \\
\hline Centropages furcatus & Centropages furcatus & NII-IV & 283 & Jump-sink & 92 & Paffenhöfer \& Knowles (1980) \\
\hline Centropages typicus & Temora longicornis & NIV-VI & 291 & Swim & 442 & Titelman (2001) \\
\hline Centropages furcatus & Temora turbinate & NII-IV & 164 & Swim & 237 & Paffenhöfer \& Knowles (1980) \\
\hline Centropages typicus & Calanus finmarchicus & NIII & 280 & Swim & 350 & Sell et al. (2001) \\
\hline \multicolumn{7}{|l|}{ Feeding current } \\
\hline Temora stylifera & Centropages furcatus & NII-IV & 227 & Jump-sink & 69 & Paffenhöfer \& Knowles (1980) \\
\hline Temora longicornis & Temora longicornis & NI & - & Jump-sink & 90 & Daan et al. (1988) \\
\hline Temora longicornis & Temora longicornis & NIV & - & Swim & 39 & Daan et al. (1988) \\
\hline Temora longicornis & Calanus finmarchicus & NIII & 280 & Swim & 250 & Sell et al. (2001) \\
\hline Temora stylifera & Temora turbinate & NII-IV & 219 & Swim & 150 & Paffenhöfer \& Knowles (1980) \\
\hline
\end{tabular}

example, the vorticity in a feeding current rotates the prey such that it-despite escape attempts - may remain in the center of the feeding current and eventually get captured (Fields \& Yen 1997b, Caparroy et al. 2000). Also, habituation to the fluid signals may exist. We observed that many nauplii responded repeatedly in the pipette flow, whereupon some were drawn into the pipette while others finally managed to escape the flow. A similar response has been observed for nauplii in flow fields of copepods (Landry 1978, Yen \& Fields 1992, Fields \& Yen 1997b). Copepods may detect a hydrodynamic signal from a nauplius entrained in its feeding current and commence an attack (Landry 1981, Visser 2001), or elicit an attack in response to a prey escape jump (Yen \& Strickler 1996). The escape strategy employed by cruising nauplii, i.e. to limit predator encounter, also diminishes the risk of provoking a predator attack by means of unnecessary and potentially dangerous flight.

Predation rates for copepod predators feeding on various nauplii of a wide size range ( 50 to $600 \mu \mathrm{m})$ often scales with prey size (e.g. Landry 1978, 1980, Landry \& Fagernes 1988). This is not surprising given that the encounter rate is strongly sensitive to prey size through direct ( $a$ in Eq. 5) and indirect (through $v$ in Eq. 5, cf. Table 5) effects on mainly the detection distance. However, when considering naupliar prey within a more constrained size category that are being cleared by a specific predator, the effect of prey behavior emerges (cf. Table 8). Nauplius motility and escape-related behavior acting at both encounter and post-encounter levels may then explain observed differences in clearance rates (Paffenhöfer \& Knowles 1980, Titelman 2001).
Predicted detectability of a large cruising Calanus nauplius is similar to that of a jump-sink nauplius of less than half its size (Fig. 6). Had such a large nauplius instead had a jump-sink behavior similar to that of a frenetically jumping Acartia nauplius, predicted detectability and encounter rates become enormous, suggesting that a jump-sink motility is not a viable strategy for larger nauplii. Also, non-cruising nauplii rely on the diffusivity of motile food for food encounter (Titelman \& Kiørboe 2003). The efficiency of 'diffusion feeding' decreases rapidly with increasing nauplius size, i.e. with $a^{-2}$ for a stationary nauplius and approaching $a^{-1}$ as jump frequency increases (cf. Eq. 6a-d in Titelman \& Kiørboe 2003). This implies that larger nauplii with jump-sink motility would experience difficulties in supporting their feeding needs, in addition to being at high predation risk. Behavioral observations, in fact, suggest that small nauplii (e.g. Temora, Centropages, Acartia, Oithona) may afford either of the observed motility strategies, while larger nauplii, such as late Calanus, Eucalanus, and Diaptomus are described as having a cruising or a feeding current behavior (review in Titelman \& Kiørboe 2003, their Tables 3 \& 4). Apparently, these considerations do not apply to copepodids, because raptorially feeding copepodids exhibit jump-sink motility (e.g. Oithona, Acartia) (e.g. Jonsson \& Tiselius 1990, Svensen \& Kiørboe 2000). The clear scaling between copepod feeding rates and prey size typically breaks down when copepodids are used as prey, even when of similar size as naupliar prey (e.g. Landry 1978, Landry \& Fagernes 1988). Copepodids may have more efficient detection and/or escape abilities that allow them to maintain an otherwise dangerous jump-sink behavior. 


\section{CONCLUSIONS}

Two extreme predator avoidance strategies related to general motility and sensitivity to hydrodynamic signals crystallize out from our data and model considerations: (1) cruising nauplii that generate weak hydrodynamic signals and modest predator encounter rates, and are poor at detecting predators remotely; and (2) nauplii with a 'noisy' jump-sink motility that generate high encounter rates, but compensate by effective remote detection of predators. Here, we have demonstrated that the motility of copepod nauplii is tightly linked to their sensitivity to hydrodynamic signals and that the size dependency involved in hydrodynamic signal perception differs between motility types (Fig. 2). Unfortunately, no remote detection or escape-jump data are available for low frequency jump-sink types such as Oithona and Oncaea. However, in terms of limiting predator encounter rates their motility is the most efficient despite the strong signals generated when jumping. In addition to affecting predation risk, the observed motility strategies are related to different feeding strategies (Paffenhöfer et al. 1996, Titelman \& Kiørboe 2003). Nauplii face behavioral trade-offs in terms of food encounter, and predator avoidance at both encounter and post-encounter levels. Just like that of any other organism, their behavior needs be interpreted in the light of both food acquisition and predator avoidance.

Acknowledgements. We thank Per Jonsson, Øyvind Fiksen and Peter Jumars for constructive comments on earlier drafts of this paper. This study was funded by a EU-TMR Marie Curie PhD Fellowship (ERBFMBICT 972833) to J.T. and a grant from the Danish Natural Sciences Research Council (9801391) to T.K.

\section{LITERATURE CITED}

Broglio E, Johansson M, Jonsson PR (2001) Trophic interaction between copepods and ciliates: effects of prey swimming behavior on predation risk. Mar Ecol Prog Ser 220:179-186

Buskey EJ, Coulter C, Strom S (1993) Locomotory patterns of microzooplankton: potential effects on food selectivity of larval fish. Bull Mar Sci 53:29-43

Caparroy P, Thygesen UH, Visser AW (2000) Modelling the attack success of planktonic predators: patterns and mechanisms of prey size selectivity. J Plankton Res 22: 1871-1900

Conley WJ, Turner JT (1985) Omnivory by the coastal marine copepods Centropages hamatus and Labidocera aestiva. Mar Ecol Prog Ser 21:113-120

Daan R, Gonzalez SR, Klein Breteler WCM (1988) Cannibalism in omnivorous calanoid copepods. Mar Ecol Prog Ser 47:45-54

Evans GT (1989) The encounter speed of moving predator and prey. J Plankton Res 11:415-417
Fields DM, Yen J (1997a) The escape behavior of marine copepods in response to a quantifiable fluid mechanical disturbance J Plankton Res 19:1289-1304

Fields DM, Yen J (1997b) Implications of the feeding current structure of Euchaeta rimana, a carnivourous pelagic copepod on the spatial orientation of their prey. J Plankton Res 19:79-95

Gallager SM (1993) Hydrodynamic disturbances produced by small zooplankton-case-study for the veliger larva of a bivalve mollusk J Plankton Res 15(11):1277-1296

Greene CH (1988) Foraging tactics and prey selection patterns of omnivorous and carnivorous calanoid copepods. Hydrobiologia 167/178:295-302

Haury LR, Kenyon DE, Brooks JR (1980) Experimental evaluation of the avoidance reaction of Calanus finmarchius. J Plankton Res 2:187-202

Jakobsen HH (2001) Escape response of planktonic protists to fluid mechanical signals. Mar Ecol Prog Ser 214:67-78

Jonsson PR, Tiselius P (1990) Feeding behaviour, prey detection and capture efficiency of the copepod Acartia tonsa feeding on planktonic ciliates. Mar Ecol Prog Ser 60:35-44

Kerfoot WC (1978) Combat between predatory copepods and their prey: Cyclops, Epischura and Bosmina. Limnol Oceanogr 23:1089-1102

Kiørboe T, Saiz E (1995) Planktivorous feeding in calm and turbulent environments, with emphasis on copepods. Mar Ecol Prog Ser 122:135-145

Kiørboe T, Visser A (1999) Predator and prey perception in copepods due to hydromechanical signals. Mar Ecol Prog Ser 179:81-95

Kiørboe T, Saiz E, Visser A (1999) Hydrodynamic signal perception in the copepod Acartia tonsa. Mar Ecol Prog Ser 179:97-111

Landry MR (1978) Predatory feeding behavior of a marine copepod, Labidocera trispinosa. Limnol Oceanogr 23: $1103-1113$

Landry MR (1980) Detection of prey by Calanus pacificus: Implications of the first antennae. Limnol Oceanogr 25: 545-549

Landry MR (1981) Switching between herbivory and carnivory by the planktonic marine copepod Calanus pacificus. Mar Biol 65:77-82

Landry MR, Fagerness VL (1988) Behavioral and morphological influences on predatory interactions among marine copepods. Bull Mar Sci 43:509-529

Lenz PH, Hartline DK (1999) Reaction times and force production during escape behavior of a calanoid copepod Undinula vulgaris. Mar Biol 133:249-258

Paffenhöfer GA (1993) On the ecology of marine cyclopoid copepods (Crustacea, Copepoda) J Plankton Res 15:37-55

Paffenhöfer GA, Knowles SC (1980) Omnivorousness in marine planktonic copepods. J Plankton Res 2:355-365

Paffenhöfer GA, Strickler JR, Lewis KD, Richman S (1996) Motion behavior of early copepodid stages of marine and planktonic copepods. J Plankton Res 18:1699-1715

Saito H, Kiørboe T (2001) Feeding rates in the chaetognath Sagitta elegans: effects of prey size, prey swimming behaviour and small-scale turbulence. J Plankton Res 23: 1385-1398

Sell AF, van Keuren D, Madin LP (2001) Predation by omnivorous copepods on early developmental stages of Calanus finmarchicus and Pseudocalanus spp. Limnol Oceanogr 46(4):953-959

Svensen C, Kiørboe T (2000) Remote prey detection in Oithona similis: hydromechanical versus chemical cues. J Plankton Res 22:1155-1166

Tiselius P, Jonson PR (1990) Foraging behavior of 6 calanoid 
copepods: observations and hydrodynamic analysis. Mar Ecol Prog Ser 66:22-33

Tiselius P, Jonsson PR, Kaartvedt S, Olsen EM, Jørstad T (1997) Effects of copepod foraging behavior on predation risk: an experimental study of the predatory copepod Pareuchaeta norvegica feeding on Acartia clausi and A. tonsa (Copepoda). Limnol Oceanogr 42(1):164-170

Titelman J (2001) Swimming and escape behavior of copepod nauplii: implications for predator-prey interactions among copepods. Mar Ecol Prog Ser 213:203-213

Titelman J, Kiørboe T (2003) Motility of copepod nauplii and implications for food encounter. Mar Ecol Prog Ser 247: 123-135

van Duren LA, Videler JJ (1995) Swimming behaviour of developmental stages of the calanoid copepod Temora

Editorial responsibility: Otto Kinne (Editor),

Oldendorf/Luhe, Germany longicornis at different food concentrations. Mar Ecol Prog Ser 126:153-161

Viitasalo M, Kiørboe T, Flinkman J, Pedersen LW, Visser AW (1998) Predation vulnerability of planktonic copepods: consequences of predator foraging strategies and prey sensory abilities. Mar Ecol Prog Ser 175:129-142

Visser AW (2001) Hydromechanical signals in the plankton Mar Ecol Prog Ser 222:1-24

Yen J, Fields DM (1992) Escape response of Acartia hudsonica (Copepoda) nauplii from flow field of Temora longicornis (Copepoda). Arch Hydrobiol Beih Ergeb Limnol 36: 123-134

Yen J, Strickler JR (1996) Advertisement and concealment in the plankton: what makes a copepod hydrodynamically conspicuous? Invertebr Biol 115:191-205

Submitted: April 29, 2002; Accepted: September 10, 2002 Proofs received from author(s): January 8, 2002 